\section{Star wars}

\section{True cost still growing \\ Washington}

INITIAL research and development on the Star Wars ballistic missile defence programme will probably cost more than $\$ 70,000$ million, according to a coalition of arms control groups opposed to the programme. The group, called the National Campaign to Save the ABM [Anti-ballistic Missile] Treaty, said last week that the usual desciption of the Strategic Defense Initiative (SDI) as a five-year, $\$ 26,000$ million research project is merely an artefact of the Pentagon's five-year planning window, and does not reflect the true extent of the effort.

With the release of the proposed 1986 budget, the programme has already become a six-year, \$33,000-million research effort; the arms control groups said that the tenyear research phase called for in SDI plans could reach as much as $\$ 100,000$ million, and drag on an extra three years, if cost overruns characteristic of Pentagon weapons-system development programmes occur.

SDI plans call for a decision on deployment to be made in 1983 . The arms control groups' report, prepared by John Pike of the Federation of American Scientists, notes, however, that the SDI office may be unable to spend its money as quickly as it hopes to receive it. While most Department of Defense programmes manage in any given year to disburse about half of the funds appropriated in that year (and about a quarter in the following year), the SDI programme has been able actually to spend only one-third of its money in the year it was appropriated.

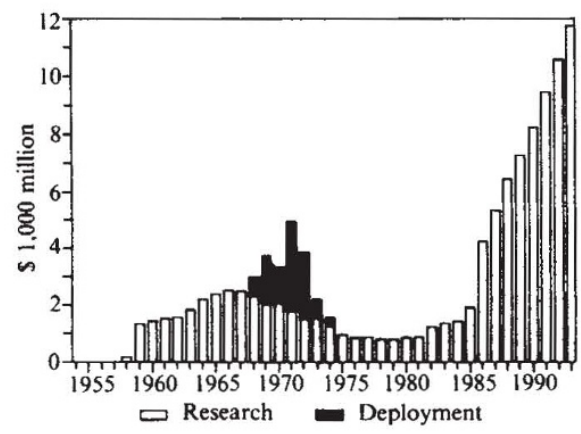

The costs of the US Strategic Defense Initiative and predecessor programmes, expressed in "constant" dollars at fiscal year 1986 price levels. The "deployment" costs refer to the deployment during the early 1970 s of the US anti-ballistic missile system.

The arms control groups' emphasis on the budgetary consequences of Star Wars appears to be a shift in strategy. Until now, the arguments against Star Wars have centred on its technical unfeasibility and its destabilizing effects on the balance of strategic power. The budgetary argument appears designed in part to counter the Reagan administration's argument that the programme is only a research effort. "Its massive budget will create pressures for deployment", Pike said. The report also charges that the programme will involve testing of actual anti-missile prototypes, possibly violating the $A B M$ treaty (which forbids any testing of space-based, air-

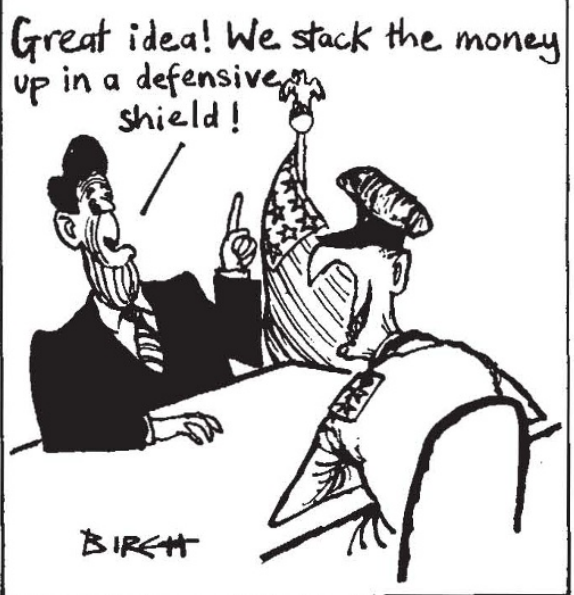

based, sea-based or mobile land-based systems or components). According to the report, the following hardware is scheduled for testing during the research and development phase:

- Booster surveillance and tracking system. Components of this midwavelength infrared system are due to be tested on early-warning satellites in the mid-1980s; operational testing, in which the system would be used to track missiles in their boost phase, is planned for the early 1990s.

- Space surveillance and tracking system. Operational capability is scheduled for the early 1990 s for this long-wavelength infrared sensing system, which may be able to detect thermal "signatures" of missiles in mid-course.

- Terminal imaging radar. A demonstration of this $\mathrm{X}$-band radar, designed to discriminate between decoys and warheads, is planned for the late $1990 \mathrm{~s}$. - Lasers and neutral particle beams. Space-based and ground tests will take place in the 1990s.

- Pointing and tracking mechanism for nuclear-pumped $\mathbf{X}$-ray lasers. A spacebased test of the pointing and tracking component is planned.

- Ground-based rocket interceptors. Tests are planned of the High Endo-Atmospheric Defense System (HEDS) as well as a follow-on to the Homing Overlay Experiment using smaller interceptors.

- Rail guns. Space-based tests of a hypervelocity launcher are planned for early $1990 \mathrm{~s}$.

- Rocket-propelled space-based launchers. Tests in space of this system, which follows the lines proposed by the High Frontier organization, are expected in early 1990 s.

Stephen Budiansky
Feedstuff hormones Europe to ban
without proof?

Brussels

Political pressure from member states of the European Community on the use of synthetic hormones in farm livestock may mean that scientific opinion is overridden. While European consumer groups, led by the Bureau of European Consumers' Unions (BEUC), prepare another veal boycott over the use of growth hormones (which increase the weight of calves and beef cattle and make them more manageable), the Commission is alarmed that a scientific report on growth promoters that it has commissioned will be preempted.

In February, BEUC accused the European Commission of procrastination in producing the report on the controversial artificial growth promoters trenbolone and zeranol (which imitate the activity, respectively, of testosterone and oestradiol). The report is being drawn up by a special scientific group on anabolic agents led by Professor Eric Lamming of the University of Nottingham and was originally due last autumn. BEUC regards the delay as an attempt by the Commission to renege on earlier commitments made in the wake of the hormone scare in 1980 in Italy, when babies fed with babyfood made with veal containing synthetic hormone residues began precociously developing sexual features, not necessarily those of their own sex.

Although European farm ministers originally said they were in favour of a ban on the use of all hormones for fattening purposes, pressure from the French and US veterinary industries as well as member states where synthetic hormones are widely used, led to a subsequent Commission ban on only the most dangerous of the synthetic hormones - stilbenes and thyrostatic substances.

As well as expressing concern for consumers' health, BEUC insists that the present 700,000-tonne beef surplus in the Community constitutes an argument against the use of growth promoters in livestock on economic grounds. Only the United Kingdom, Ireland and Luxembourg use synthetic hormones. West Germany permits the use of natural hormones, but the use of all hormones for fattening purposes is banned in the remaining member states.

After looking at the evidence compiled by the Lamming group, the Community's scientific, veterinary, animal nutrition and food committees last April urged the introduction of strict precautions in using natural hormones (17 $\beta$-oestradiol, testosterone, progesterone and their less stable additives) and more effective monitoring. BEUC wants a strict system of controls as well as labelling stating clearly that the meat contains no added hormones. 